\title{
URBANIZATION AND IT IMPACTS TO LAND SURFACE TEMPERATURE ON SMALL MEDIUM SIZE CITY FOR YEAR 1991, 2011 AND 2018: CASE STUDY KOTA KINABALU.
}

\author{
Ricky Anak Kemarau ${ }^{1}$, Oliver Valentine Eboy ${ }^{1}$ \\ ${ }^{1}$ Geography Program, \\ Faculty of Social and Science and Humanities, \\ Universiti Malaysia Sabah, \\ 88400 Kota Kinabalu, Sabah, Malaysia.
}

Correspondence: Ricky Anak Kemarau (ricky.geo2005@gmail.com)

\begin{abstract}
Transformation of land cover vegetation toward urban areas causes the temperature at urban higher to compare to suburban and rural areas, namely urban heat island (UHI) effect. The UHI has a negative impact, such a stroke heat, air pollution, green gasses emission, and electric consumption. UHI studies at a tropical country still limited due to the containment of cloud cover. Besides that, studies only focus on big cities which have residents above than 2 million. The outcome this studied important to enhance our knowledge of urban heat effect at small-medium cities and guidelines to policymaker and urban planner to discover there has effectively taken to decrease the effect of urban heat at the hot spot area. The main goal of this research about to discovered influence of urban growth and selected urban index, namely the Normalized Difference Built Index (NDBI) to LST. NDBI is an index which denotes intensity of urban built up. In the first step, we generate the LST and NDBI from Landsat 8 OLI at year 2018 and Landsat 5 TM for the year 2011 and 1991. Second, we applied the unsupervised classification of Landsat 8 OLI and Landsat $5 \mathrm{TM}$ to generate the land cover maps for the years 1991, 2011, and 2018. Third of our method to examine the relationship between Land surface temperature (LST) and NDBI. The higher value NDBI is a hot spot, and the low value is a cold spot. In the last step, we applied for Change Detection analysis using GIS to examine the land cover change between 1991 and 2018. Our results show the higher the value of NDBI and LST at the centre of the city and the lowest value at
\end{abstract}


vegetation land cover. The transformation of land cover vegetation to urban increase at countryside area and out-of-town and significantly increase of distribution of UHI. On another hand, the shows positive relationships between LST and NDBI. The output of the study provides a guideline for policymakers and town designers to develop to toward city zero carbon, sustainable and health.

Keywords: LST, Urbanization and NDBI, Surface Urban Heat Island, Remote Sensing, and GIS

\section{Introduction}

The increasing population and the offer of better socio and economic activities have been attracting the population to move from village to town areas. The movement of the residents from village to town zones caused the urban expansion and an increasing transformation from vegetation land cover to human-built in recent decades (United Nations, 2018) to fulfill the demand of the population. In 2007, regarding United Nations (United Nations, 2015), estimated $66 \%$ of world population will live at town city. On other hand at 2007, for first time in human history the population of urban exceeded than rural area population. The phenomenon of urbanization has the transformation of the land cover vegetation to build up human man, which concerns the impact on waste, air and water pollution, and climate change. The climate change because of green gasses emission and required more energy consumption to comfort humans in urban areas in tropical country and summer season at temperate climate because of the UHI effect. UHI, where the atmospheric and surface temperature of town and countryside areas higher compared to rural environments (Howard, 1818). The first observed conducted by Luke Howard from the years 1772 until 1864. The Literature review mentioned the main index applied denotes to built-up land properties namely Index Based Built up (IBI), the normalized difference built-up index (NDBI), and Urban Index (UI) (Berger et al., 2017; Peng et al., 2016; Liang et al., Estoque et al., 2017; Zhao et al., 2018; Zhang et al., 2019; Feng et al., 2018). The all studied mentioned above was applied at climate temperate city areas where the towns are more advanced compare to the urban tropical less studied because of cloud containment, in which thermal and visible wavelength cannot penetrate the cloud. However, several studies involving the tropical and subtropical cities was done in mega cities at Asia namely Mumbai, Delhi in India, Dhaka in Bangladesh, Hanoi in Vietnam, Singapore and Bangkok in Thailand (Feng et al., 2018; Chen et al., 
2014). However, all the studied mentioned only focus on UHI analyses of single cities and mega-cities (Ranagalage et al., 2018; Fu et al., 2015; Chen et al., 2014). The motivation of this study because (Zhou et al., 2019) stated that the principal UHI and SUHI concentration did not exist because of the strong background rural area. Because of this, most of the studies done mentioned above have a population of more than 5 million; there still not studies focus on medium-small cities size such a Kota Kinabalu with the population 224700 (United Nations, 2018). The output from this study expected to enhance our knowledge regarding SUHI and LST for mediumsmall cities. On another hand, a few studies directed to report the long-term land cover change because, in subtropical and tropical towns, the cloud covers always the major problem in optical satellite data namely as Landsat successions datasets cant penetrate the cloud. This study able to help more understand the SUHI at medium city size. This objective of this study research is to identified the relationship of the selected urban index, NDBI, and land cover for an urban area, water, and vegetation and discover the relationship of NDBI and urban growth on land surface temperature.

\section{Study area}

Kota Kinabalu is located on Borneo, which capital city of the state of Sabah, Malaysia. The population of Kota Kinabalu 244,700 for the year 2017 (United Nations, 2018). Zhao(2019) has proposed to focus on medium small-sized cities which with below 2 million urban population.

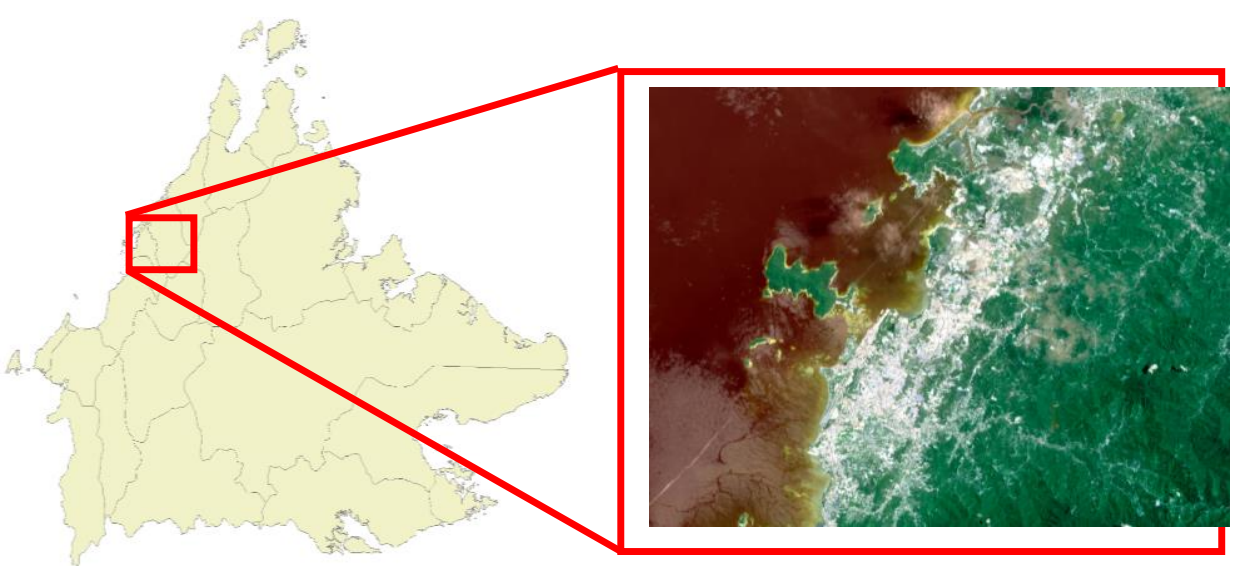

Figure 1shows study area. 


\section{Methodology}

\section{Dataset}

Table 1 shows the detailed of the dataset

\begin{tabular}{cccc}
\hline Data & $\begin{array}{c}\text { Spatial resolution } \\
\text { (meters) }\end{array}$ & $\begin{array}{c}\text { Thermal resolution } \\
\text { (meters) }\end{array}$ & Data Acquisition \\
\hline $\begin{array}{c}\text { Landsat } 5 \\
\text { TM }\end{array}$ & 30 & 120 & $1991-06-14$ \\
$\begin{array}{c}\text { Landsat } 5 \\
\text { TM }\end{array}$ & 30 & 120 & $2011-01-21$ \\
$\begin{array}{c}\text { Landsat } 8 \\
\text { OLI }\end{array}$ & 30 & 100 & $2018-08-27$ \\
\hline
\end{tabular}

This study chooses the 3 data because of the cloud cover less from 10\%. The Landsat data were first required pre-processed to reduce the effect of illumination and atmosphere attenuation. The pre-processing included the calibration, and employing NDBI, generate the Land surface temperature, linear correlation, results, and the graph for representing our result.

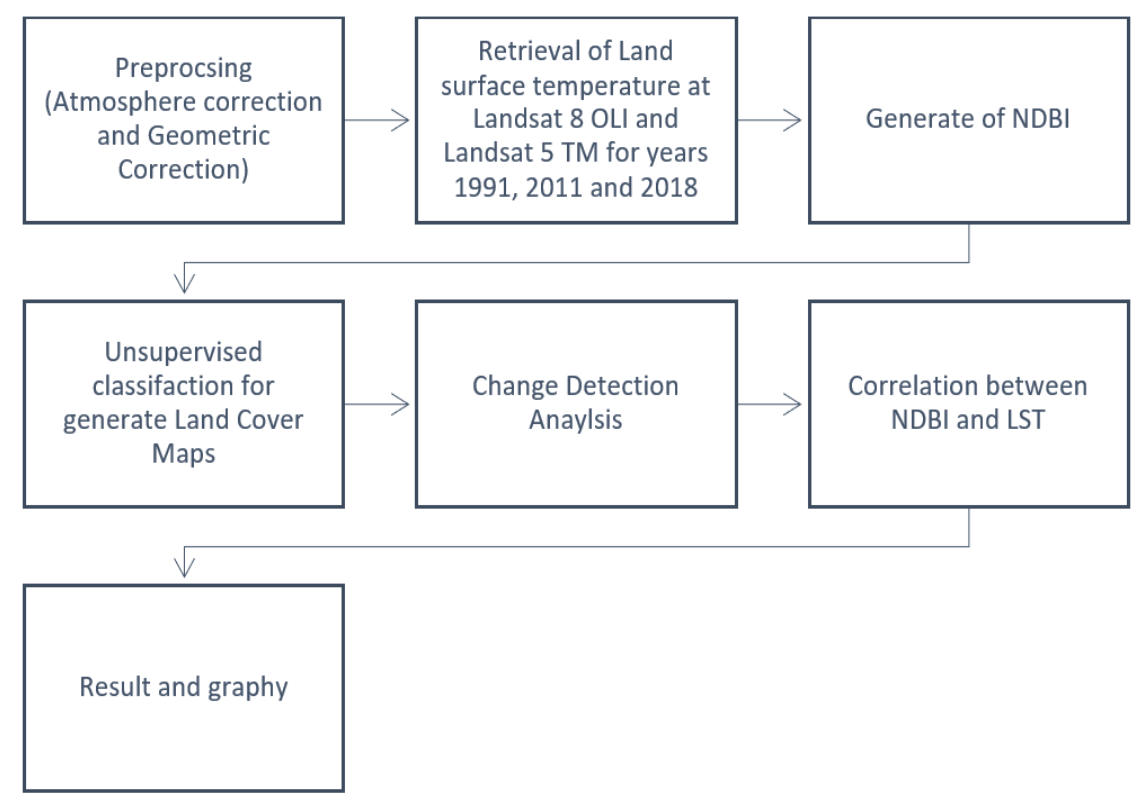

Figure 2: Flow methodology 


\section{Convert Digital Number to Land Surface Temperature at Landsat 5 TM.}

The pre-processing task of the thermal band has done by ENVI 5.3 software. The atmospheric pre-processing correction very important to reduce and remove the atmosphere effect at thermal infrared data. The thermal band at Landsat $5 \mathrm{TM}$ is a band 6 . The first step is an estimated sensor radiance where there the digital numbers (DN). We applied the method which well established and applied (Artis et al., 1982) as referring to the equation (eq) below.

$$
L_{\lambda}=\left(\frac{L M A X_{\lambda}-L M I N_{\lambda}}{Q_{\text {calmax }}-Q_{\text {ralmin }}}\right)-\left(Q_{\text {cal }}-Q_{\text {calmin }}\right)+\left(L M I N_{\lambda}\right)
$$

The follow eq. Above, Where $\mathrm{L} \lambda$,s cell value as radiance in $\mathrm{W} /\left(\mathrm{m} 2 * \mathrm{~s}{ }^{*} \mu \mathrm{m}\right)$, LMAX $\lambda$ is the spectral radiance, scaled to QCALMAX in $\mathrm{W} /\left(\mathrm{m} 2 * \mathrm{sr}^{*} \mu \mathrm{m}\right)$ and LMIN $\lambda$ is Spectral radiance that scaled to QCALMIN in $\mathrm{W} /(\mathrm{m} 2$ $\left.{ }^{*} \mathrm{sr}^{*} \mu \mathrm{m}\right)$. QCALMAX is a maximum quantized calibrated pixel value (equivalent to LMAX) in DN: 255 and QCALMIN is a minimum quantized calibrated pixel value (equivalent to LMIN) in DN:

\begin{tabular}{ll}
\hline $\operatorname{LMAX}_{\lambda}$ & 15.303 \\
$\operatorname{LMIN}_{\lambda}$ & 1.238 \\
\hline
\end{tabular}

Table 2: Information on Landsat 5 TM.

The information on Landsat $5 \mathrm{TM}$ was provided at the metadata file Landsat $5 \mathrm{TM}$. The second of eq below, which by assuming that the earth's surface is a black body with the spectral emissivity of 1 , at-sensor spectral radiance transformed to eff ective at-sensor brightness temperature according to Eq. (Artis et al., 1982):

$$
T_{\mathrm{B}}=\frac{k_{2}}{\ln \left(\frac{k_{1}}{L_{\lambda}}+1\right)}
$$

where $T_{\mathrm{B}}$ is the eff ective at-sensor brightness temperature in Kelvin $(\mathrm{K})$, and $\mathrm{K} 1$ and $\mathrm{K} 2$ are the calibration constants. For this case study, the Landsat-5 $\mathrm{TM}, \mathrm{K} 1$ was $607.76 \mathrm{~W} /(\mathrm{m} 2 \mathrm{sr} \mu \mathrm{m})$, and $\mathrm{K} 2$ was $1260.56 \mathrm{~K}$. In the third step, due to the at-sensor brightness temperature obtained by Eq. above, which was related to a black body, spectral emissivity had to be corrected to estimate LST related to the gray body. The emissivity corrected LST calculated by using Eq. (Artis et al., 1982): 


$$
L S T=\frac{T_{B}}{1+\left(\lambda T_{R} / \alpha\right) I n \varepsilon}
$$

Where LST is the land surface temperature in K, TB refers to the eff ective at-sensor brightness temperature in $\mathrm{K}, \lambda$ stands for the wavelength of the emitted radiance in meters (eff ective wavelength is $11.457 \mu \mathrm{m}, 11.269 \mu \mathrm{m}$, and $10.904 \mu \mathrm{m}$ for the thermal bands of Landsat-5 TM, respectively, based on (Artis et al., 1982) with $\alpha=1.438 \times 10-2 \mathrm{mk}$ ), and $\varepsilon$ is the surface emissivity. Then LST calculated in Kelvin was converted to the Celsius degree, as shown in Eq.:

$$
\operatorname{LST}\left({ }^{\circ} \mathrm{C}\right)=\operatorname{LST}(\mathrm{K})-273.15
$$

\section{Generated of Land Surface Temperature From Landsat 8 OLI}

The surface thermal radiation was recorded at spectral bands of Thermal Infrared Sensor (TIRS) 10 in sensor Landsat 8 OLI. The pre-processing was required to reduce the effect of atmosphere effect on thermal data. The surface temperatures were retrieved based on algorithms (Jimenez et al., 2014; Bao et al., 2019) applied. The values of the digital number (DN) converted to spectral radiance $\mathrm{L} \lambda$ at the top of the atmosphere, according to Eq.

$$
L_{\lambda}=\mathrm{ML} \times \mathrm{Qcal}+A_{L}
$$

where $\mathrm{L} \lambda$ stands spectral radiance, $\mathrm{W} /(\mathrm{m}$ srum $) 2$; $\mathrm{ML}$ represents the rescaled gain corresponding to a specific band, $\mathrm{W} /(\mathrm{m} \mathrm{sr} \mu \mathrm{m}) 2 ; A_{L}$ means the re-scaled bias corresponding to a specific band, $\mathrm{W} /(\mathrm{m} \mathrm{sr} \mu \mathrm{m}) 2$. After that, atsensor brightness temperature $\mathrm{Tb}$ (Unit: $\mathrm{K}$ ) was extracted from TIRS 10, corresponding to the OLI sensor through Eq.:

$$
T_{b}=K_{2} /\left(\ln \left(\frac{K_{1}}{l_{\lambda}}\right)+1\right.
$$

Where $\mathrm{k} 1$ and $\mathrm{k} 2$ are constants, with values of 774.89 (Unit: $\mathrm{W} /(\mathrm{m} \mathrm{sr} \mu \mathrm{m}) 2$ ) and 1321.08 (Unit: W), Lst subsequently obtained after the emissivity correction of ground radiance $\mathrm{B}(\mathrm{LST})$ (Unit: K) via a mono window algorithm developed by Qin et al. (2001).

$$
\mathrm{NDVI}=\frac{P N I R-P R E D}{P N I R+P R E D}
$$

NDVI reference measured to refer to Eq below, where $\rho$ NIR and $\rho$ RED refer to the reflectance values of the near-infrared and red bands. The calculation 
of the NDVI is important because, subsequently, the proportion of vegetation $\left(\mathrm{P}_{\mathrm{v}}\right)$, which is highly related to the NDVI, and emissivity $(\varepsilon)$, which is related to the $P_{v}$, must be calculated.

$$
\mathrm{PV}=\left(\frac{N D V I-N D V I s}{N D V I v-N D V I S}\right)^{2}
$$

$\mathrm{Pv}$ is the percentage of vegetation in a pixel. $\mathrm{Pv}$ is the vegetation proportion calculated based on Carlson and Ripley (1997), by using Eq.:

$$
\mathrm{E}=\varepsilon \mathrm{v} \mathrm{Pv}+\varepsilon \mathrm{g}(1-\mathrm{P})+4<\mathrm{d} \varepsilon>\mathrm{Pv}(1-\mathrm{Pv})
$$

Where $\varepsilon$ is ground emissivity, $\varepsilon v$ is the emissivity of pure vegetation cover area $(=0.985)$, $\varepsilon g$ stands for the emissivity of the pure bare ground area $(=0.960),<\mathrm{d} \varepsilon>$ is the revised parameter by average 0.01 (19). Then LST calculated in Kelvin was converted to the centigrade degree, as shown in Eq.:

$$
\mathrm{LST}=(\mathrm{TB} /(1+(\lambda * \mathrm{~TB} / \mathrm{C} 2) * \operatorname{Ln}(\varepsilon)))-273.15
$$

Where LST is kelvin (K), BT is that-sensor brightness temperature (Kelvin), $\rho=\mathrm{hc} / \sigma, \sigma=$ Boltzmann constant $(1.38 \times 10-23 \mathrm{~J} / \mathrm{K}), \mathrm{h}$ is Planck's constant $(6.626 \times 10-34 \mathrm{~J} / \mathrm{s}), \mathrm{c}$ is the velocity of light $(2.998 \times 108 \mathrm{~m} / \mathrm{s})$, and $\mathrm{e}$ is the emissivity.

\section{Land Indices: NDBI.}

NDBI is an represented the concentration of the urban built-up area. NDBI is important as an analytical tool for characterizing land development, urbanization, and land surface parameters (Chen et al., 2014).

$$
N D B I=\frac{S W I R-N I R}{S W I R+N I R}
$$




\section{Results and Discussion}

Figure 3 shows LST maps for the years 1991, 2005, and 2018.

LST map for the year 1991

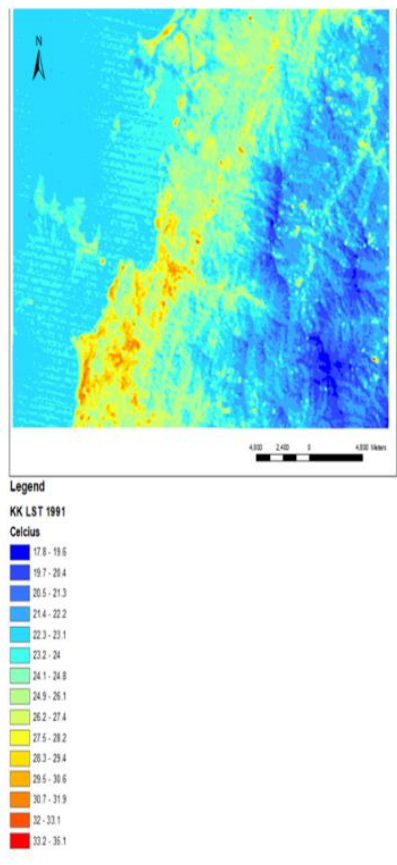

LST map for the year 2011

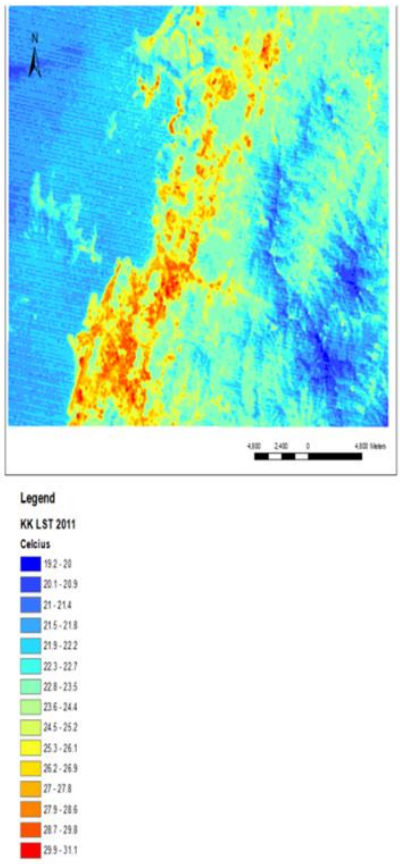

LST map for the year 2018

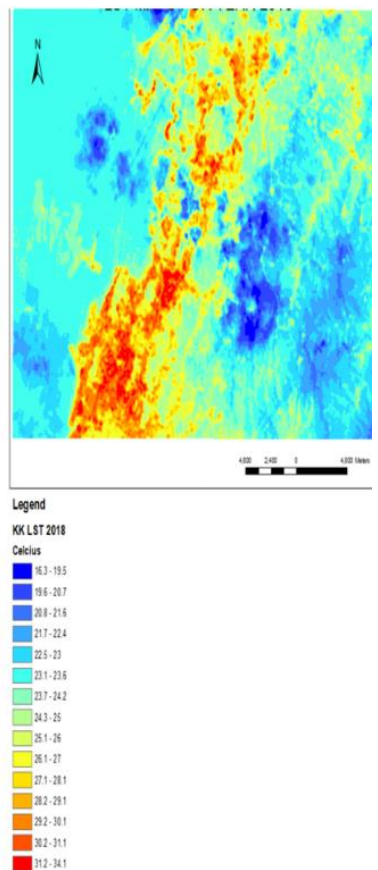

Figure 3: LST Maps for the years 1991, 2011, and 2018.

The first result shows there excite of urban heat island, even the population city below 2 million. The results same achieved which has done conducted at Putra (Siti et al., 2018) and Johor Bahru (Afsaneh et al., 2018). The urban areas indicate the value of LST high compared to areas of suburban and rural areas. Most of the pixels which represented higher value LST are an urban area. The high built-up concentration of the area can be clearly identified and represented hot spot areas. The most of hot spot is an area study which totally of compact with the building which no content of vegetation and water surrounding the study area. The cold spot has been having the low built-up concentration of an area on LST can be identity evidently and relocated at rural areas or suburban or non-urban zone with the urban zone which temperature of this zone is lower. The value of LST at area surrounding water content namely river and vegetation lower compare to LST at town areas. The red colour in map or figure 2 indicates high 
temperatures in centre of town. On other hand shows blue colour shows low temperature at vegetation land cover and water contents. The temperature is low in the countryside/suburban because of the green vegetation. The example of suburban area University Malaysia Sabah. The value of mean LST UMS is 27 and 28-degree Celsius for the years 2011 and 2018 compared to the canter of city Kota Kinabalu with mean 30 and 31 for the year 2011 and 2018. The urban areas show higher temperature pixels due to the existence of impervious surfaces like built-up areas and anthropogenic materials in urban areas compared to rural areas. They explain the importance of landscape vegetation very important in reducing of urban heat effect (Zhang et al., 2017; Artis et al., 1982). The pattern of LST for the study areas does have changed to grow to a suburban and rural area as follows the urbanization process. It is clear from the maps of LST the urban area grows to north-east of area study. The result shows the thus proving the existence of a strong SUHI over Kota Kinabalu. Out of all, the three-year LST map shows visible SUHI effects with strong contrast in temperature of the urban and rural areas. In general, the expansion SUHI influenced by population growth and in-migration because Kota Kinabalu provides a better offer of social and economical to people of Sabah. The second factor because of most education, industrial, commercial activities concentrated in Kota Kinabalu.

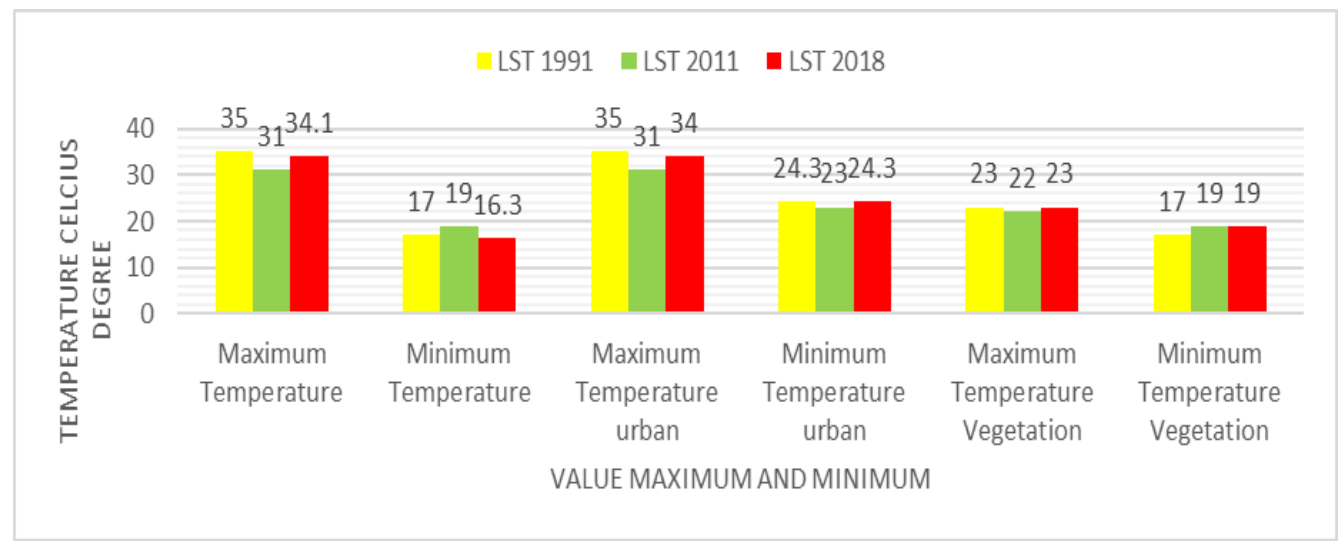

Graph bar 1: Value maximum and minimum temperature for the years 1991, 2011, and 2018.

The graph bar 1 shows the maximum value for urban area LST temperature for the year (34 Celsius degree) 1991, (31 Celsius degree) 2011 and (34 Celsius degree) 2018 were 35, 31, and 34. And the hand vegetation maximum value 23 Celsius degree, 22 Celsius degree, and 23 Celsius degree for the years 1991, 2011, and 2018. 


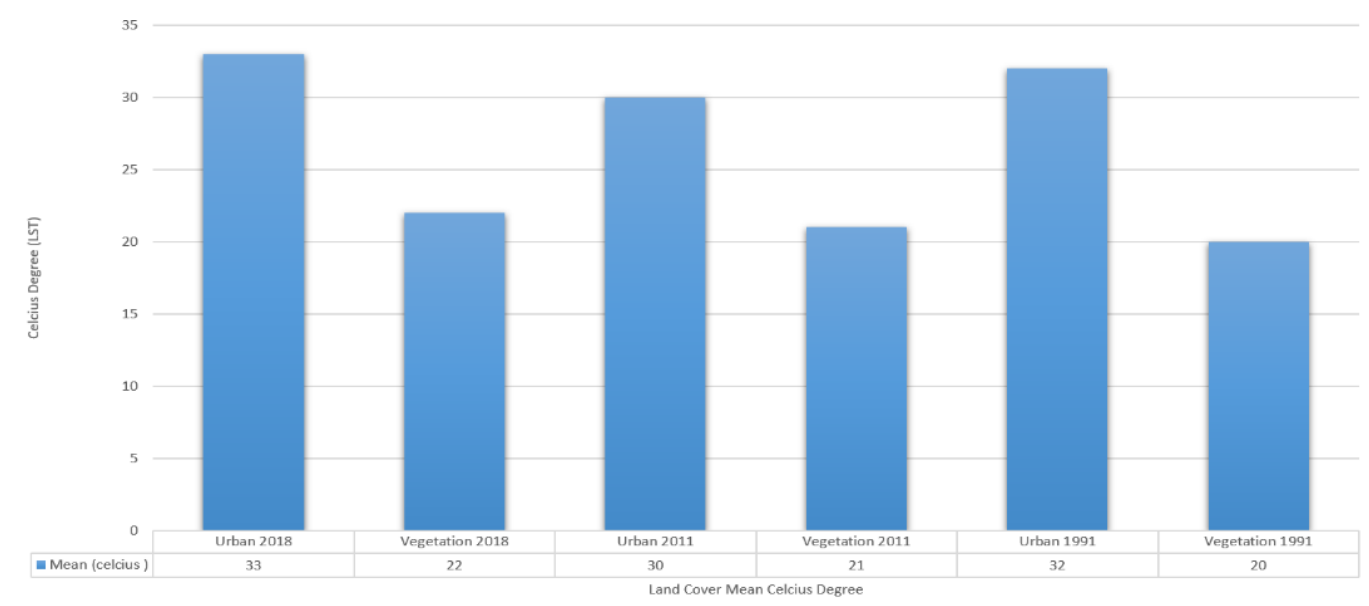

Graph Bar 2: Value means LST (Celsius Degree) every land cover for years 1991, 2011, and 2018. Based on the graph bar 2 explained the mean LST (Celsius) at urban area high than vegetation cover as mentioned 33-degree Celsius for 2018, 30-degree Celsius for the year 2011 and 32 Celsius degree at the year 1991. There is different 11 Celsius between LST between land cover urban and vegetation for the year 2018, 9-degree years 2011, and 12degree Celsius in the year 1991. 


\section{Normalized Difference Built Index (NDBI)}

NDBl Map for the year 1991

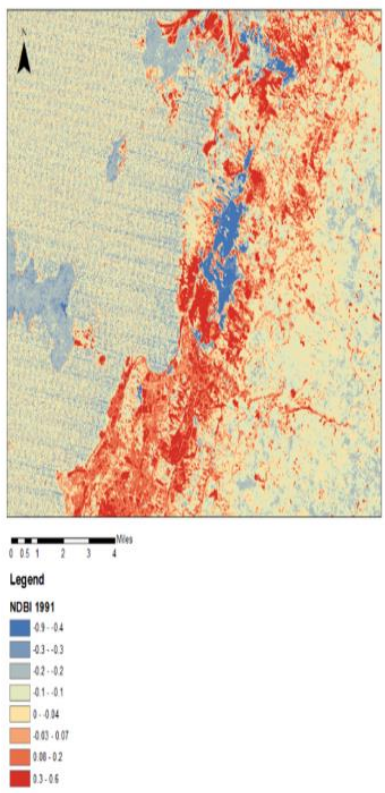

NDBI Map for the year 2011
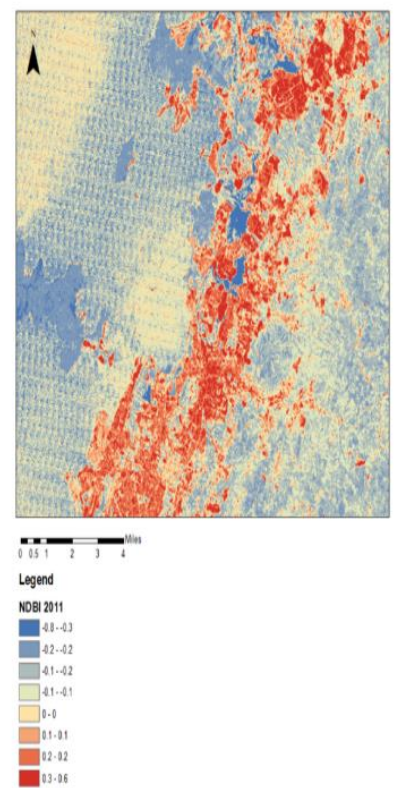

NDBI Map for the year 2018

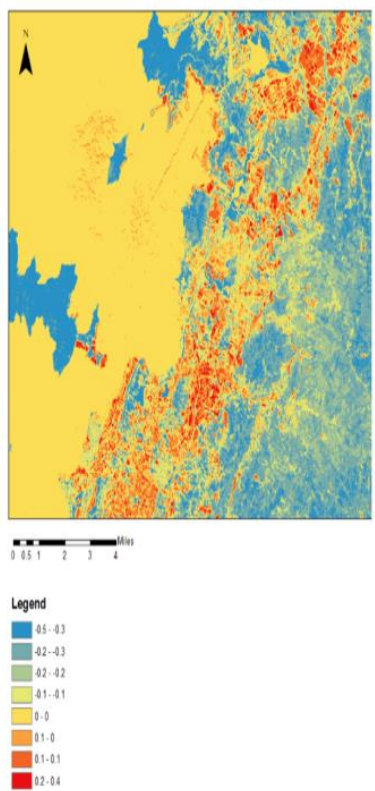

Figure 4: The NDBI map for years 1991, 2011 and 2018

The NDBI developed to automate to identity the built-up and use for mapping the process of built-up (20). The value of NDBI is a one is the highest of building, and the -1 represents no content of built up. For this study, the maximum for NDBI for 1991 is 0.6 , and the minimum is a -0.9 . The maximum for 2011 is 0.6 and minimum -0.8, and for 2018 the maximum is a 0.4 and minimum -0.5. Figure 4 shows that the high value of NDBI at the centre of the city, which content compact of built-up, which no content of natural creatures such as vegetation and water. The NDBI pattern mostly in the town centre but the value NDBI which more than 0.1 extended from the urban centre to the suburban. For this study, the NDBI grow up to the northeast of the east area of study, as mentioned in the map of NDBI for the year 1991, 2011 and 2019. Figure 4 shows there was an increased area of NDBI from the years 1991, 2011, and 2018. From that figure, they clearly explain to us the value of NDBI for the years 1991 and 2011. The highly is 0.6, and for 2018 the high value is 0.4. This because of for 1991 most area has value $0.3-0.6$ the vegetation is clear off for development particular at Likas area which construction Sepanggar Port, University Malaysia Sabah, and settlement. The maps NDBI 2011, the land cleared off for developing the 
commercial centre and settlement particular at Likas basin. The maps 2018 most the land which cleared off for man use has to done completed, and the local authority has planted for the urban landscape.

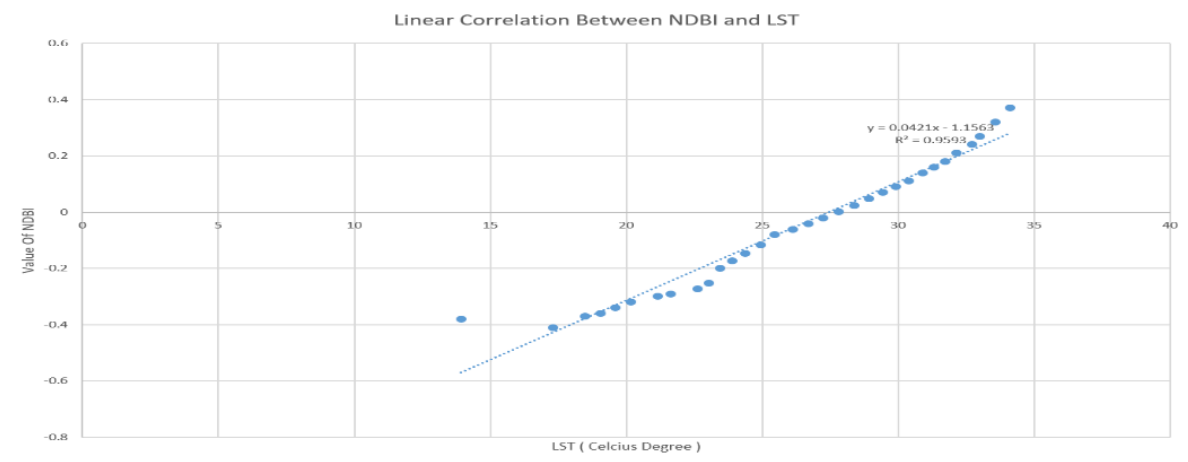

Figure 5: The linear correlation between NDBI and LST

The study uses the 32 random samplings for performing the relationship between the LST and NDBI data. The result of correlation shows the relationship strong relationship between LST and NDBI. The relationship between LST and NDBI was significantly positive with $\mathrm{R}^{2} 0.95$ as mentioned at figure 5 . 


\section{Land Cover and Change Detection}

Land Cover Map The Year 1991
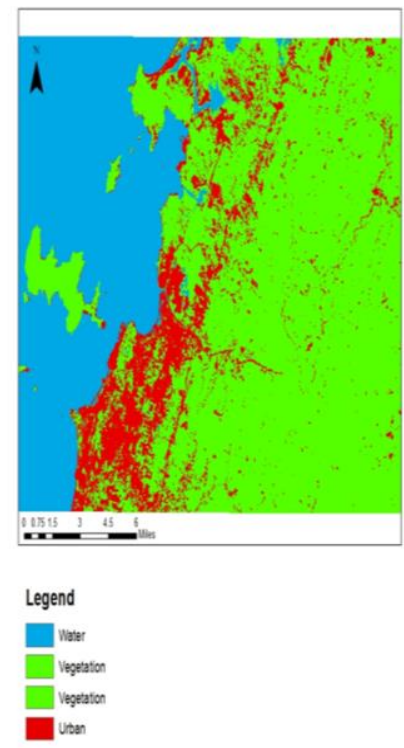

Land Cover Map The Year 2011
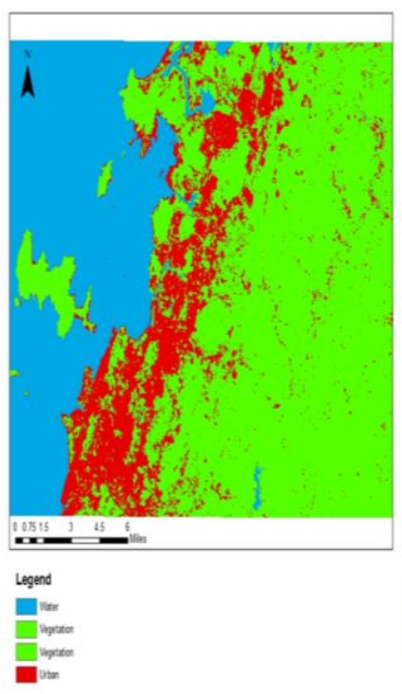

Land Cover Map The Year 2018

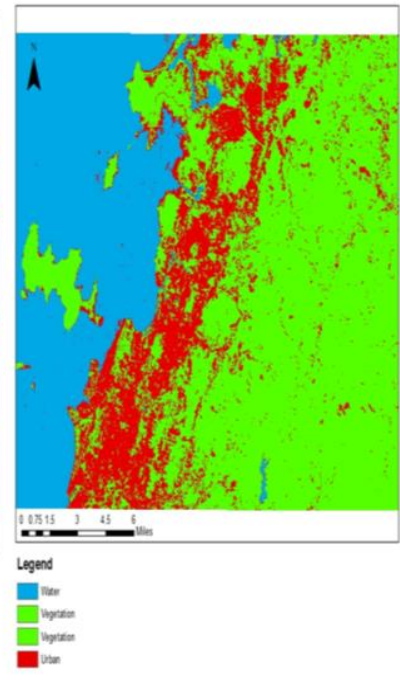

Figure 6: Land Cover Map for years 1991, 2011, and 2018.

The result shows that the land cover urban area continues to increase, and spatial pattern distribution was different between the three selected years. The land cover urbanization was mainly focused in the centre of the city in 1991 but expanded to the northeast of study areas, which previously is rural and suburban. 


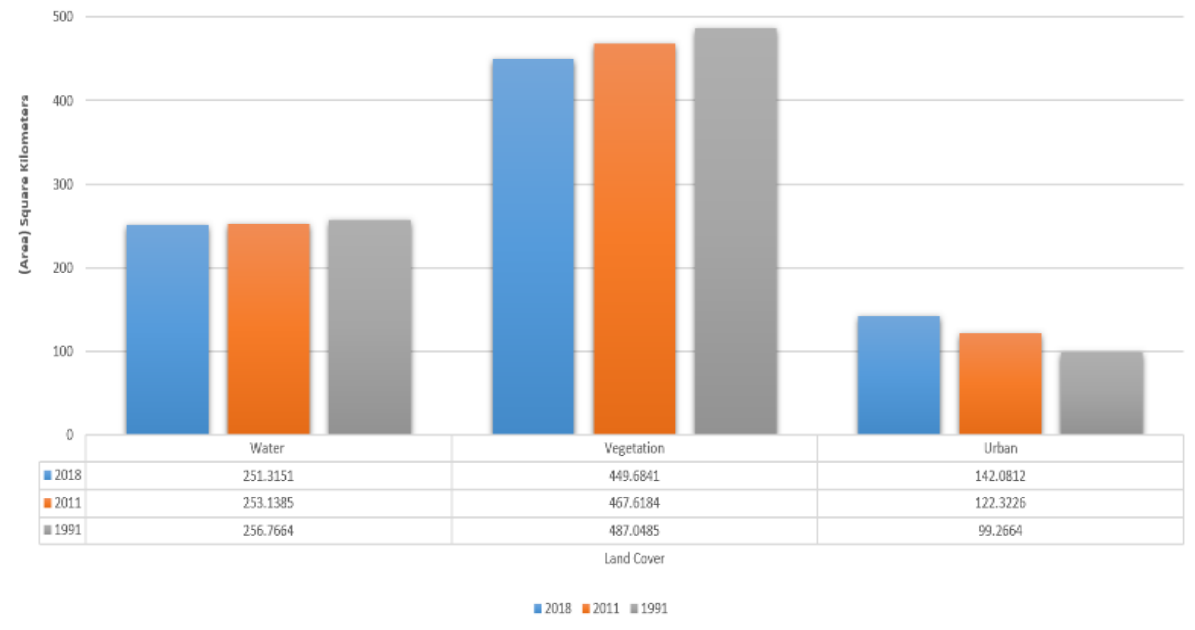

Graph Bar 3 shows the total area (Square Kilometer) land cover for years 1991, 2011, and 2018.

Graph bar 3 shows the areas of land cover for the years 1991, 2011, and 2018. The area of urbanization increases every selected year from 99.266 square kilometres to 122.322 square kilometres in the year 2011 and increases to 142.08 square kilometres in the year 2018. The area of land cover water decreases from 251.31 square meters for the year 1991 to 256.766 square kilometres in the year 2018. This because of activities of reclamation sea for built Hotel Sutera Harbour, settlement for Gaya Island, and Sepanggar Port. On the other hand, it shows the area of vegetation decrease form from 487.04 square kilometres in the year 1991 to 449.68 square kilometres in 2018. 


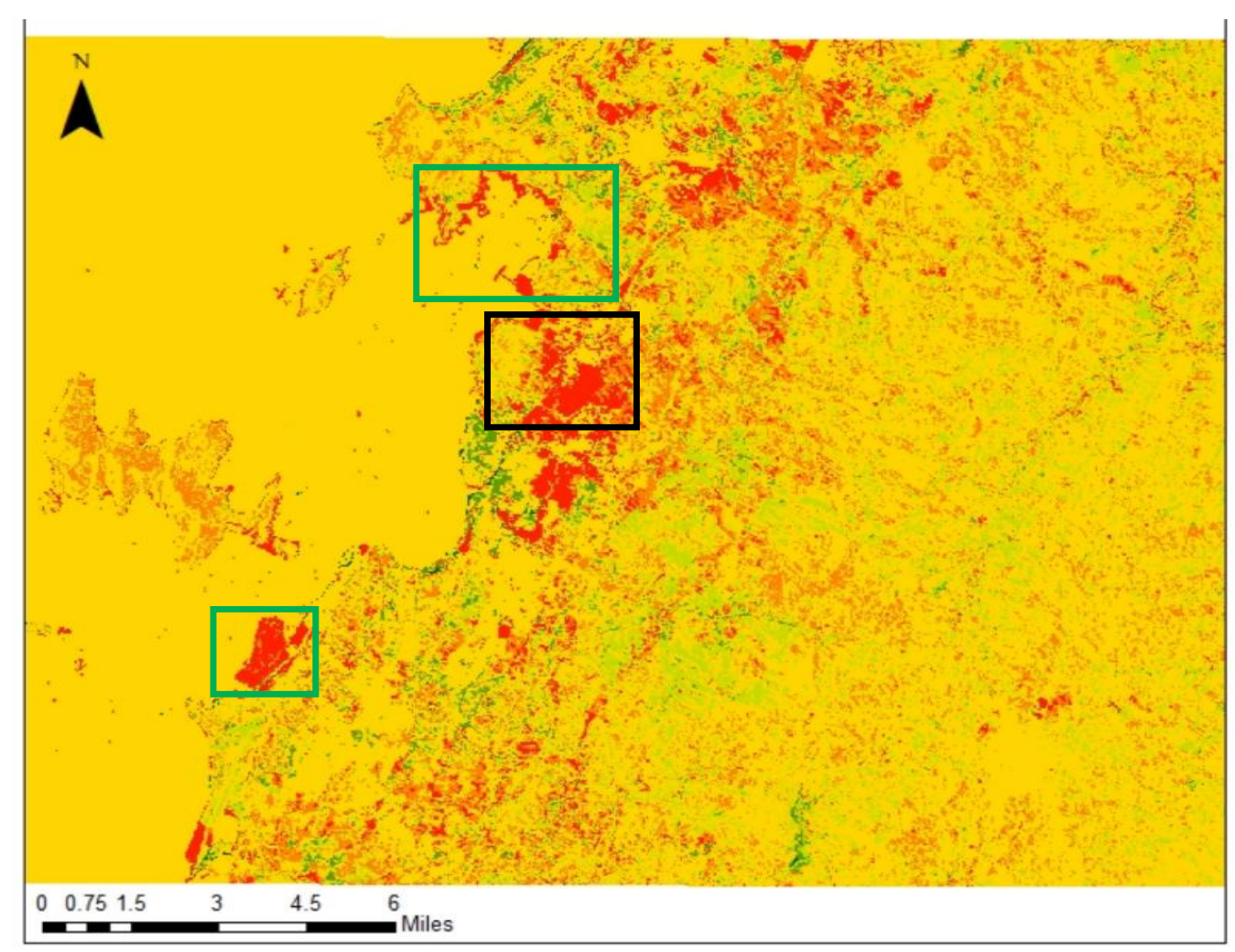

\section{Legend}

Change Detection Between years 1991 and 2018

Value

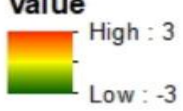

Figure 7: Change Detection for Land Cover between the years 1991 and 2018.

The red colour with pixel value three which, presents great change between 1991 and 2018. The main change from vegetation land cover to an urban area relocated Likas Basin, which places transform from vegetation cover area to housing, Government Building, High Learning Education Institute University Malaysia Sabah, and commercial centre such 1 Borneo Supermarket as marked with black square shape. Second, the big change is a reclamation area from water land cover to built-up land covers such as the Sutera Harbour Resort and Sepanggar Port, which marked green square shape. 


\section{Conclusion}

The land cover change and NDBI have been impacting the LST pattern were studied. However, because of the limitation of data free from cloud covers the very difficult to understand the long trend of spatial UHI, NDBI, and land cover change. The data of Landsat has been a wavelength visible and thermal band which, as mentioned at the dataset, cannot penetrate the cloud. The result discovered the SUHI in Kota Kinabalu was excited in smallmedium of city-sized with a population below 2 million. The high intensity of the SUHI distributed at the center and expanded northeast of area study. Results discovered that the land cover changes for a built-up area increase 5.1 from 1991 to 2018, decrease the water and vegetation land cover with 1.4 $\%$ and $4.33 \%$ for each of them. The results show there strong positive relationship between NDBI and LST. This study suggests that the scenery of vegetation and water bodies has the potential to decrease the urban heat effect. The effectiveness of the mitigation of urban heat effects can assessed, and monitoring uses the long trend of remote data sensing. The remote sensing and GIS technology are effective and reasonable costs for monitoring the LST pattern for large-area study. From this study, we can improve knowledge to understanding LST and SUHI and supportive for legislators or town planners to express the method to reduce the effects of SUHI effect to people and increase the quality of life urban population for achieving green city policy.

\section{Acknowledgment}

Thank NASA policy, which because gives free access to data of Landsat generation.

\section{References}

Artis, D. A., \& Carnahan, W. H., 1982. Survey of emissivity variability in thermography of urban areas. Remote Sensing of Environment, 12, 313-329.

Artis, D. A., \& Carnahan, W. H. (1982). Survey of emissivity variability in thermography of urban areas. Remote Sensing of Environment, 12, 313-329.

Afsaneh Sheikhi, Kasturi Devi Kanniah, 2018, Impact of land cover change on urban surface temperature in Iskandar Malaysia, Chemical Engineering Transactions, 63, 25-30 DOI:10.3303/CET1863005. 
Bao-Jie Hea, Zi-Qi Zhaob, Li-Du Shenc, Hong-Bo Wangb, Li-Guang Lib (2018) An approach to examining performances of cool/hot sources in mitigating/ enhancing land the surface temperature under different temperature backgrounds based on Landsat 8 image. Sustainable Cities and Society 44 (2019) 416-427

Berger, C.; Rosentreter, J.; Voltersen, M.; Baumgart, C.; Schmullius, C.; Hesse, S. 2017 Spatio-temporal analysis of the relationship between 2D/3D urban site characteristics and land surface temperature. Remote Sens. Environ. 2017, 193, 225-243. [CrossRef].

Chen, A.; Yao, S.; Sun, R.; Chen, L. (2014) How many metrics are required to identify the effects of the landscape pattern on land surface temperature? Ecol. Indi. 2014, 45, 424-433

Estoque, R.C.; Murayama, Y.; Myint, S.W. (2017) Eff ects of landscape composition and pattern on land surface temperature: An urban heat island study in the megacities of Southeast Asia. Sci. TotalEnviron. 2017, 577, 349-359. [CrossRef] [PubMed].

Feng, Y.; Li, H.; Tong, X.; Chen, L.; Liu. Y. 2018. Projection of Land Surface Temperature considering the effects of the future on land change in the Taihu Lake Basin of China. Glob. Planet.Chang.2018, 167,23-24.

Fu, P.; Weng, Q.H. (2015). A time-series analysis of urbanization induced land Use and land cover change and its impact on land surface temperature with Landsat imagery. Remote Sens. Environ. 2016, 175, 205-214.

Howard, L., 1818. The Climate of London; 1. W. Phillips: London, UK, 1818.

Jiménez-Muñoz, J.C., Sobrino, J.A., Skokovíc, D., Mattar, C.,\& Cristóbal, J.(2014). Land surface temperature retrieval methods from Landsat-8 thermal infrared sensor data. IEEE Geoscience and Remote Sensing Letters, 11, 1840-1843.

Peng, J.; Xie, P.; Liu, Y.; Ma, J. 2016. Urban thermal environment dynamics and associated landscape pattern factors: A case study in the Beijing metropolitan region. Remote Sens. Environ. 2016, 173, 145-155. [CrossRef]. 
Liang, B.; Weng, Q. (2008) Multi-scale analysis of census-based land surface temperature variations and determinants in Indianapolis, United States. J. Urban Plan. Dev. 2008, 134, 129-139. [CrossRef].

Ranagalage, M.; Estoque, R.C.; Zhang, X.; Murayama, Y. (2018) Spatial changes of urban heat island formation in the Colombo district, Sri Lanka: Implications for sustainability planning. Sustainability, 2018, 10, 1367. [CrossRef]

United Nations .2018. UN Department of Economic and Social Aff airs, The World 's Cities in 2018; United Nations: New York, NY, USA, 2018.

United Nations. 2015. UN Department of Economic and Social Aff airs, World Urbanization Prospects: The 2014 Revision, Highlights; United Nations: New York, NY, USA, 2015.

United Nations. UN Department of Economic and Social Aff airs, The World 's Cities in 2018; United Nations: New York, NY, USA, 2018.

Siti Aekbal Salleh, Zulkiflee Abd.Latif, Wan Mohd. Naim Wan Mohd, Andy Chan. 2018. Land Covers and Climate Impacts on Land Surface Temperature in Putrajaya, Malaysia. eISSN 2514-751X (C) 2018. The Authors. Published for AMER ABRA CE-Bs by E-International Publishing House, Ltd., UK.

Zhang, Y., Sun, L. (2019). Spatial-temporal impacts of urban land use a land cover on land surface temperature: case studies of two Canadian urban areas. Int. J. Appl. Earth Obs. Geoinf. 75, 171-181.

Zhang, H.S.; Wang, T.; Zhang, Y.H.; Dai, Y.R.; Jia, J.J.; Yu, C.; Li, G.; Lin, Y.Y.; Lin, H.; Cao, Y. (2018) Quantifying short-term urban land cover change with time-series Landsat data: A comparison of four diff erent cities. Sensors, 2018, 18, 4319

Zhao, H.; Zhang, H; Miao, C; Ye, X.; Min. (2018) Linking Heat Source-Sink Landscape Patterns with Analysis Of Urban Heat Island: Study on the FastGrowing Zheng Zhou City in Central China. Remote Sens.2018,10,1268.

Zhou, D.; Bonafoni, S.; Zhang, L.; Wang, R. Remote sensing of the urban heat island effect in a highly populated urban agglomeration area in East China. Sci. Total Environ. 2018, 628-629, 415-429. [CrossRef] [PubMed] 
Zhou, Jingfeng Xiao, Stefania Bonafoni, Christian Berger, Kaveh Deilami, Yuyu Zhou, Steve Frolking, Rui Yao, Zhi Qiao, and José A. Sobrino. 2019. Satellite Remote Sensing of Surface Urban Heat Islands: Progress, Challenges, and Perspectives. Remote Sens. 2019, 11, 48; doi: 10.3390/rs11010048.www.mdpi.com/journal/remotesensing.

Zhang, Y.; Murray, A.T.; Turner, B.L., II. 2017. Optimizing green space locations to reduce daytime and night-time urban heat island effects in Phoenix, Arizona. Lands. Urban Plan. 2017, 165, 162-171. 